\title{
Relationship of Career Assessment Examination Result to the Academic Performance of Secondary School Students
}

\author{
Elymar A. Pascual \\ elymarpascual@rocketmail.com \\ Department of Education, Nagcarlan District, Laguna, Philippines, 4002
}

\begin{abstract}
This study focused on investigating the performance of a private high school graduating students in the yearly conducted National Career Assessment Examination given by the Department of Education. The researchers would like to know if the present curriculum content used by a private high school is in line with the national standard. To serve this purpose, the NCAE results of a private high school for two school years were gathered and recorded. Then their academic performances in Mathematics, Science and English (base on final grade) were noted. T-test was used to see if there is a significant difference between these two factors. It was found out that the mean percentile rank of a private high school students in Science for the past two years was 67.05 with a standard deviation of 21.90. In Mathematical Ability, their mean percentile rank was 79.23 with a standard deviation of 16.51. And the mean percentile rank for English was 79.80 with a standard deviation of 18.48. On the other hand, the mean academic performance in Science was 85.50 with a standard deviation of 4.80. In Mathematics, the mean academic performance was 85.41 with a standard deviation of 5.64. And in English, their mean academic performance was 84.00 with a standard deviation of 4.64 . Using t-test, it was concluded that there is no significant difference between the result in NCAE and the students' academic performance. Base on these findings and conclusion, recommendations directed to specific persons were laid down, and future researchers were encouraged to replicate the study for the future graduating students of a private high school.
\end{abstract}

Keywords: Mathematics; Science; English; career assessment; academic performance

\section{Introduction}

Every country has their own way of assessing their students' academic achievement. They have formulated standardized exams that will measure their citizens' attainment of national standard. For example, in United States of America, they have SAT or ACT. Vast majortiy of colleges in USA accept either the two as requirement for admission. In United Kingdom, they have GCSE which is also well known to other countries. In mainland China, they annualy conduct the National College Entrance Examination which is parallel to what we now call National Career Assessment Examination (NCAE) here in the Philippines.

This year is third in the annual adminstration of NCAE. Two school years ago, it was conducted on the month of January, but last school year and this school year, they were conducted on the month of August. The primary purpose is to guide students on the career suited for them on their tertiary education. But news declare that it is now being studied and being proposed in the Congress so that it will be mandatory and the result in NCAE will be commandatory on the course which will be given to them on college. In other words, they will not be allowed to take course that does not fit them, base on their NCAE performance. In other news, it was alleged that the Department of Education (DepEd) is doing this to cater to foreign needs of skilled workers here and abroad. Student members of League of Filipino students (LFS) oppose this motive of the Philippine governement because they are thinking that if that is the case, Filipinos will be shrinked down to skilled workers and that will lead to a poorer economy, and the area of research, development, and technology will be neglected.

These are just some issues connected to the present move of DepEd in promoting NCAE as a way of guiding students in the choosing the course for their college life. 
The DepEd extended their effort of guiding Filipino students by including the private schools in NCAE. For three years now, private secondary schools' teaching staff and leaders were alerted to prepare their students in this government project, in which, private schools are actively responding.

One of those private schools that heeded the mandate of DepEd was the private school where the author of this study formerly taught. Every year, a teaching staff was sent to the division meeting to get the gist and the instruction from superior with regards to the exam. Representative from the District used to monitor a private high school before and during the examination to check if the exam is properly administered.

But question arise as to how well the graduating students in a private high school faired in the standardized test, and how well they perform compared to other schools. In this notion, the researchers of this paper were stimulated to conduct a systematic study that will elicit a conclusive answer to those concerns. They started to collect data available in the Principal's office, and were able to process this information to produce meaning statistical data. This paper is the product of that endeavor.

\subsection{Statement of the Problem}

This study will focus on finding out the NCAE performance of the fourth year high school students in a private institution in relation to the school academic performance.

Specifically, it will seek to find answer to the following questions:

1.) What is the mean level of NCAE performance of fourth year high school students in terms of the following areas:

a.) Science;

b.) English (Reading Comprehension and Verbal Ability); and

c.) Mathematics;

2.) What is the mean level of academic performance of fourth year high school students in the following areas:

a.) Science;

b.) English; and

c.) Mathematics; and

3.) Is there a significant difference between the NCAE performance and academic performance of fourth year high school students in a private institution?

\subsection{Significance of the Study}

The result of this study will be of benefit to the following group of persons:

- Science, English and Mathematics Teachers - The National Career Assessment Examination highlights the evaluation of students' aptitude including the three major areas: Science, English and Mathematics. At the same time, these three subjects composes the core subjects in today's DepEd curriculum. It is in this sense that Science, English and Mathematics teachers of a private high school should know and be benefited by this study in order to enhance, further develop and keep up with the present standard the Philippine Education has.

- Parents - Parents are the partners of the school in nurturing their child's full potential. The knowledge of how well the students perform in the NCAE gives the parents the assurance that the school is doing their best to receive quality education, as stated in the mission and vision of the school.

- Students - This study is an encouragement to the students for them to value education and give their utmost not only for themselves but ultimately for the glory of the One who gave them talents and intelligence. 
- Future Researchers - As pioneer of studies in its kind, this study serves as a starting point for future researchers to delve more on the subject. NCAE is conducted every year so it is highly suggested that this study be replicated for the purpose of investigating the school performance with reference to national standard.

\subsection{Scope and Limitation}

The National Career Assessment Exam (NCA) is being administered for two years now. a private high school participated in those two years. In the first school year, eight fourth year students, and in the second school year, fifteen fourth year students took the said exam. Their NCAE performance specifically, in Science, English (Reading Comprehension and Verbal Ability) and Mathematics will be correlated to their final academic grade in Science, English and Mathematics.

\section{Review of Related Readings}

This section of the study lays down what has been said or written about the topic being undertaken. The readings presented here open issues that serve as guide for the researchers. Also, this chapter includes the hypothesis, the research paradigm and the definition of terms used in the proceedings of this paper.

\subsection{Review of Related Readings}

The students led by LFS boycotted the exam in belief that the NCAE's goal is to "discourage the students from taking up college courses and is instead an authoritarian measure to force them to take up voctech."

"The DepEd want to force us to go to voc-tech instead of going to college just because that is what's in-demand. But what will happen if five, ten years from now the market changes its demands and these jobs goes out of uso? What will happen to those students that we misled into not taking up college?" he explained. (LFS Members Boycott NCAE, 2007)

The objectives of NCAE laid down by DepEd (NCAE, 2006) are the following:

- Assess abilities of students in areas essential for post-secondary careers

- Provide students information that will help them make wise career decisions, specifically in terms of pursuing COLLEGE or TECH-VOC diplomas or ENTREPRENEURIAL opportunities

- Provide basis for selection of scholars for post-secondary Programs

The domains measures by NCAE are the following:

1.) GENERAL SCHOLASTIC APTITUDE (GSA)

$\begin{array}{ll}\text { Scientific Ability } & 40 \text { items } \\ \text { Reading Comprehension } & 60 \text { items } \\ \text { Verbal Ability } & 60 \text { items } \\ \text { Mathematical Ability } & 60 \text { items }\end{array}$

2.) TECHNICAL-VOCATIONAL APTITUDE (TVA)

3.) ENTREPRENEURIAL SKILLS (ES)

4.) NON-VERBAL ABILITY (NVA)

5.) OCCUPATIONAL INTEREST (OI)

More than half of the 1.3-million senior high school students who took the National Career Assessment Examination (NCAE) on Jan. 17 showed a high aptitude for technical-vocational courses, the Department of Education (DepEd) said Wednesday. "The results validate our decision to really put stress on our technical-vocational programs," former Education Secretary Jesli Lapus told a news conference. The NCAE, he pointed out, is "by far the best tool our young graduates can use to properly assess their own skills and inclinations. And this will enable them to make more effective career decisions."

"We expected the relatively low performance of students in the GSA since this is consistent with the results of the National Achievement Test. And we have been saying for so long the inability of government in 
the past to cope with the huge resource demands of a growing student population has placed us on a catch-up 1850 mode," he said. (www.inquirer.net, 2007)

If the tests find the students to have scored high in math and science [nonverbal], they will be advised to take engineering, architecture or computer science, he (Jesli Lapus) said. If the tests show the students excel in verbal, they woul be advised to take liberal arts, teaching or others that really fit their talent. Lapus said that besides this, there is a domain in NCAE that will measure the technical and vocational aptitude of students, so that if the latter is inclined to these fields, they will be advised to focus on these. He said NCAE will also provide an option for the students to pursue entrepreneurship as there are some who may want to put up their own businesses instead of continuing with their college studies. This is like career guidance, so it is called career assessment, he said. (NCAE Soon to Replace NCEE, 2006)

\subsection{Hypothesis}

This is a tentative solution to the problem posted at the beginning of the study:

There is no significant difference between the NCAE result and the academic performance of the students of private high school.

\subsection{Research Paradigm}

The two frameworks below serve as a quick guide on the purpose of the research and as a quick glance on the subject matter being studied

Figure 1. The Research Paradigm

IV

NCAE Result in
a.) Science
b.) English
c.) Mathematics

DV

Academic Performance - General Average in
a.) Science
b.) English
c.) Mathematics

Figure 1 shows the research paradigm with the independent and dependent variables. Under the independent variable is the NCAE Result in three major areas: Science, English and Mathematics. On the other hand, the dependent variable is the Academic Performance of the fourth year students as reflected in their final general average in their report card. The two variables are connected with a line segment, signifying a possible relationship between them.

\subsection{Definition of Terms}

The following terms appear in the entire study and they are now here defined according to its universal understanding, according to how it is used in this study, and according to how they are measured in the research.

- National Career Assessment Examination Result - Jesli Lapus, the former DepEd Secretary, said that the NCAE Result if a "...tool [for] our young graduates [that they] can use to properly assess their own skills and inclinations... this will enable them to make more effective career decisions." NCAE Result in this study refers to the percentile ranking of the fourth year students in national standard. The rankings are specified for different areas: Science, Math and English. The rankings are forwarded by the DepEd to every student and a copy is also given to school heads.

- Academic Performance - Encarta 2005 defines academic as scholarly and intellectual, as opposed to vocational or practical. Performance means the effectiveness of the way somebody does his or her 
job. Academic performance in this paper means the overall performance of the student in a subject. That includes the day to day quizzes, classroom participation, submission of requirements, monthly and periodical exams. The academic performance of the students in this paper is based on the final average of each subject as reflected in their report card.

\section{Research Design and Methodology}

This chapter contains the discussion of the research design applied to obtain conclusive findings for the study being conducted. It also includes the population under study, the procedure followed in gathering pertinent data, and the appropriate statistical treatments used to answer the questions posted at the beginning of this study.

\subsection{Research Design}

This paper made use of a descriptive style of making research. Data were gathered from primary and secondary sources, were arranged accordingly, and were analyzed and studied for possible correlation or dependence. This style of research is applied for the present study because survey and experimentation are not necessary to answer the questions posted at the beginning of this study.

\subsection{Population}

The two batches who took NCAE on the previous years were the subjects of this research. For the first school year, 7 out of 8 students were available at that time to take the NCAE. For the second school year, all of the 15 students were able to take the NCAE.

\subsection{Data Gathering Procedure}

With regards to the NCAE, data were obtained from the Principal's record of individuals result in different areas: Mathematical Ability, Scientific Ability, Verbal Ability and Reading Comprehension. On the other hand, final average when the fourth year students graduate were obtained from the pertinent records as complied by the Principal.

\subsection{Statistical Treatment}

Simple mean was used to get the students' performance in NCAE and their academic performance. For the possible correlation of these two variables, t-test was used. This treatment is appropriate in looking for significant difference between two or more sample means.

\section{Presentation, Analysis and Interpretation of Results}

This chapter highlights the data gathered and the result of the statistical treatment done. They are presented in tabular form. Analysis and interpretation follow after every table.

4.1. The NCAE Result and the Academic Performance of a Private High School

Table 1. NCAE Result and Academic Performance of a Private High School Students

\begin{tabular}{|c|c|c|c|c|c|c|}
\hline \multirow[b]{2}{*}{ Students } & \multicolumn{3}{|c|}{ NCAE } & \multicolumn{3}{|c|}{ ACADEMIC PERFORMANCE } \\
\hline & SA & MA & ENG & SCI & МАТН & ENG \\
\hline First School Year & & & & & & \\
\hline
\end{tabular}




\begin{tabular}{|c|c|c|c|c|c|c|}
\hline \multirow[b]{2}{*}{ Student 1} & & & & & & \\
\hline & 32 & 87 & 98 & 89 & 91 & 889 \\
\hline Student 2 & 72 & 93 & 100 & 93 & 93 & 93 \\
\hline Student 3 & 72 & 86 & 94 & 83 & 87 & 84 \\
\hline Student 4 & 21 & 86 & 78 & 81 & 86 & 83 \\
\hline Student 5 & 32 & 64 & 84 & 81 & 80 & 83 \\
\hline Student 6 & 95 & 44 & 50 & 75 & 79 & 77 \\
\hline Student 7 & 46 & 81 & 92 & 87 & 81 & 86 \\
\hline \multicolumn{7}{|c|}{ Second School Year } \\
\hline Student 1 & 50 & 81 & 62 & 82 & 83 & 79 \\
\hline Student 2 & 44 & 50 & 34 & 80 & 77 & 81 \\
\hline Student 3 & 64 & 57 & 54 & 78 & 81 & 78 \\
\hline Student 4 & 91 & 96 & 93 & 89 & 92 & 88 \\
\hline Student 5 & 68 & 90 & 81 & 82 & 81 & 83 \\
\hline Student 6 & 93 & 99 & 96 & 91 & 93 & 89 \\
\hline Student 7 & 64 & 60 & 57 & 84 & 80 & 77 \\
\hline Student 8 & 64 & 57 & 63 & 84 & 80 & 78 \\
\hline Student 9 & 72 & 81 & 89 & 88 & 94 & 84 \\
\hline Student 10 & 90 & 93 & 94 & 87 & 85 & 87 \\
\hline Student 11 & 68 & 84 & 86 & 92 & 81 & 80 \\
\hline Student 12 & 97 & 100 & 99 & 90 & 96 & 92 \\
\hline Student 13 & 78 & 86 & 81 & 89 & 85 & 87 \\
\hline Student 14 & 90 & 93 & 94 & 87 & 87 & 88 \\
\hline Student 15 & 72 & 75 & 81 & 89 & 87 & 86 \\
\hline
\end{tabular}

* The values under NCAE English is the combination of Verbal Ability and Reading Comprehension.

Table 1 on the previous page shows the NCAE result of the two batches of fourth year students. In Scientific Ability (SA), their mean percentile rank is 67.05 with a standard deviation of 21.90. In Mathematical Ability (MA), their mean percentile rank is 79.23 with a standard deviation of 16.51 . Meanwhile, the mean percentile rank for English is 79.80 with a standard deviation of 18.48.

The same table shows the academic performance of the students as reflected in their final average in Science, Mathematics and English. Their mean academic performance in Science is 85.50 with a standard deviation of 4.80. In Mathematics, the mean academic performance is 85.41 with a standard deviation of 5.64. And in English, their mean academic performance is 84.00 with a standard deviation of 4.64.

4.2. t-test for NCAE Results and Academic Performance

Table 2. t-test for NCAE Results and Academic Performance t-Test: Two-Sample Assuming Equal Variances

SCIENCE

\begin{tabular}{l|r|r|}
\hline & \multicolumn{1}{|c|}{ NCAE } & Academic \\
\hline Mean & 67.05 & 85.50 \\
Variance & 479.47 & 23.02 \\
Observation & 22 & 22 \\
df & 42 & \\
t Stat & -3.86 & \\
t Critical & 1.68 & \\
\hline
\end{tabular}

MATH

\begin{tabular}{|l|r|r|}
\hline & NCAE & Academic \\
\hline Mean & 79.23 & 85.41 \\
Variance & 272.47 & 31.78 \\
Observation & 22 & 22 \\
df & 42 & \\
t Stat & -1.66 & \\
t Critical & 1.68 & \\
\hline
\end{tabular}

ENGLISH

\begin{tabular}{|l|r|r|}
\hline & \multicolumn{1}{|c|}{ NCAE } & Academic \\
\hline Mean & 79.80 & 84.00 \\
Variance & 341.44 & 21.52 \\
Observation & 22 & 22 \\
df & 42 & \\
t Stat & -1.04 & \\
t Critical & 1.68 & \\
\hline
\end{tabular}


Table 2 shows the t-test for the two variables under study. Since the values of $t$ Stat are less than the value of $\mathrm{t}$ Critical, the hypothesis is accepted. There is no significant difference between the NCAE Performance and the Academic Performance of a private high school students. The result in NCAE can be predicted through the students' academic performance in Science, Math and English.

\section{Summary, Conclusion and Recommendations}

This part recapitulates the important points in this study. It lines up the summary of findings, the conclusion made based on the significant findings, and the recommendations directed to specific group of persons who are in position to implement the necessary actions.

\subsection{Summary of Findings}

Two batches of fourth year students were population for this study. The first batch was composed of 8 students (one was absent during NCAE, making it seven only) while the second was composed of 15 students. This gave a total of 22 students.

Three specific questions were raised at the beginning of the study:

- What is the mean level of NCAE performance of fourth year high school students in Science, English and Mathematics;

- What is the mean level of academic performance of fourth year high school students in Science, English and Mathematics;

- Is there a significant difference between the NCAE performance and academic performance of fourth year high school students in a private high school?

It was found out that the NCAE mean percentile rank of the 22 students in Scientific Ability (SA) was 67.05 with a standard deviation of 21.90; in Mathematical Ability (MA), it was 79.23 with a standard deviation of 16.51; and in English, it was 79.80 with a standard deviation of 18.48.

In academic performance, they have a mean of 85.50 in Science with standard deviation of 4.80; 85.41 in Mathematics with a standard deviation of 5.64; and 84.00 in English with standard deviation of 4.64.

T-test shows a stat value of -3.86, -1.66 and -1.04 for Science, Mathematics and English respectively, while a critical value of 1.68 for all areas.

\subsection{Conclusions}

Based on the findings that resulted on a careful computation of available data, the following conclusions were formulated:

- UECS students perform well in the past two years of NCAE. The mean percentile rank of 67.07, 79.73 and 79.80 in Science, Mathematics and English respectively, mean that they have outscored $67.07 \%, 79.73 \%$ and $79.80 \%$ of the total number of examinees nationwide in those three areas mentioned.

- UECS students have an average academic performance, as reflected in their mean performance of 85.50, 85.41 and 84.00 in Science, Mathematics and English respectively.

- UECS students' NCAE performance has no significant difference to their academic performance, because, using the t-test, the stat values are less than the critical value. This means that their academic performance is a reflector of their NCAE performance, and vice versa.

\subsection{Recommendations}

The conclusion that resulted out of this study made the researchers to come up with the following suggestions and recommendations: 
- That Science, English and Mathematics teachers of a private high school continue using the curriculum that they have, and if possible, make an effort to have a curriculum development that will raise the school's standard, and at the same time lead students towards better academic achievement.

- That parents be partners of school in educating their children, as the school cannot perform their duty well without the cooperation of parents in terms of Christian guidance, discipline at home and moral and spiritual motivation and support students will achieve more.

- That students continue having good study habit, as the result of their academic performance and NCAE performance shows their real ability and aptitude, which will be their guides in taking tertiary courses.

- That future researchers replicate the effort made by the present researchers by conducting similar study for the present and future NCAE results and academic performance, and if possible, relate it to other areas that will help students perform well in both areas.

\section{References}

Asian Development Bank. (2017). Philippines: Implementing the Senior High School Support Program. April 16 , 2017. https://www.adb.org/projects/48284-001/main

China Education Center, Ltd. (2017). Primary and Secondary $\quad$ Education $\quad$ in $\quad$ China. April 16 , 2017. http://www.chinaeducenter.com/en/cedu/psedu.php

Department of Education, Philippines. (2017). 1.8-m students to take career assessment exam. April $14,2017$. Encarta. (2005) http://www.deped.gov.ph/regions/region-x/regional-press- releases/18-m-students-takecareer-assessment-exam

Govph. (2017). The K to 12 Basic Education Program. April 14, 2017.http://www.gov.ph/k-12/

LFS members boycott NCAE, Tells DepEd to 'stop acting like a recruitment agency'August 27, 2007

NCAE, Republic of the Philippines, Department of Education. (2006)

NCAE soon to replace NCEE, Manila Times. (18 November 2006)

UNESCO Bangkok. (2014). Education Systems in ASEAN+6 Countries: A Comparative Analysis of Selected Educational Issues. April 16, 2017. http://unesdoc.unesco.org/images/0022/002267/226757E.pdf

www.inquirer.net, DepEd: Test for HS seniors shows aptitude for tech-voc, (March 22nd, 2007) 